\title{
A Study of the Feasibility and Potential Implementation of Metro-Based Freight Transportation in Newcastle upon Tyne
}

\author{
Alex Dampier ${ }^{1} \cdot$ Marin Marinov $^{2}$
}

Received: 9 June 2015/Revised: 9 July 2015/Accepted: 27 July 2015/Published online: 19 August 2015

(C) The Author(s) 2015. This article is published with open access at Springerlink.com

\begin{abstract}
This paper discusses the concept of using a metropolitan railway network to transport freight directly to a city centre from the surrounding businesses. Specifically we look in depth at the Tyne and Wear Metro system, situated in Newcastle upon Tyne, to determine if such a scheme would be feasible. Through research into the modes of transport available, along with a review of literature and case studies, it was found that the current method of transporting the majority of freight by road is unsustainable and damaging to both the environment and local communities. Other options for the transportation of freight have been reviewed, and results showed that a modal shift will be necessary in the near future. The system was then modelled using software provided by the Department for Transport, which demonstrated that the implementation of such a scheme would provide vast accident savings, a reduction in the number of casualties on the road, and a monetary saving as a result of the lower casualty rate. The conclusion was reached that the scheme is viable; however, further research and study are necessary before implementation.
\end{abstract}

Keywords Urban freight - Metro - Metropolitan rail networks $\cdot$ COBALT $\cdot$ Defra traffic calculator

Marin Marinov

marin.marinov@ncl.ac.uk

1 Mechanical and Systems Engineering School, Newcastle University, Newcastle upon Tyne, UK

2 NewRail, Mechanical and Systems Engineering School, Newcastle University, Newcastle upon Tyne, UK

Editor: Jing Teng

\section{Introduction}

The transportation of freight throughout the country has a huge effect on Britain's economy, and both large and small businesses alike rely daily on the collection and transportation of goods. In 2010, 1489 million tonnes of goods were lifted in the UK [17, 18], $82 \%$ of which were transported by road. Rail, in comparison, had just $5 \%$ of total modal share [45]. After a peak in 2007, registered numbers of HGVs have been falling, but due to an increase in the size of preferred lorry, the volume of goods transported remains largely unchanged [21, 22].

Given that the vast majority of goods are delivered within a $50 \mathrm{~km}$ radius of the journey start point [35], there has been much research undertaken into the potential impact of using light rail systems such as inner city metros and trams to transport freight within our urban areas [5]. This paper aims to establish whether such a system could be implemented using the Metro network in Newcastle upon Tyne, to deliver goods which originate from the local area directly into the heart of the city. A potential scheme has been developed, and an in-depth study of the town of Killingworth to the north of Newcastle has been completed, to assess the impact that such a scheme could have.

The outline of the proposed scheme is as follows:

(1) All goods bound for the city centre are taken by each business to a micro-consolidation centre at Palmersville, the nearest Metro station to Killingworth. This facility could simply be based on the platform, utilizing the existing infrastructure. All businesses selected for the trial are a maximum of 3 miles away from Palmersville, so the use of a conventionally powered vehicle would not have a large effect on emissions. In time, it would be desirable to transfer 
this initial drayage leg to an ultra-low emissions vehicle (ULEV), to cut $\mathrm{CO}_{2}$ emissions.

(2) Goods are condensed into one trainload, and loaded onto a modified Metro train, repurposed for the transportation of freight. This may be made easier by the use of standardised 'Bento Boxes', to allow for easy differentiation between goods from each company, and also to increase manoeuvrability. The train would be dedicated to freight transportation, thus minimising the disruption to passengers.

(3) The train departs from Palmersville Metro station and arrives at a track situated between Jesmond Metro station and Manors Metro station, used only late at night by Nexus to transport trains back to the maintenance depot. This track holds great potential for the building of a distribution centre, as it is only a short distance from the city and is unused for the vast majority of the day.

(4) Goods would be sorted and taken the last mile to businesses through the use of bicycle couriers and electric vans, using a scheme similar to that used by GNewt Cargo (Sect. 2.6).

This scheme would reduce the numbers of vehicles on the road, reduce the $\mathrm{CO}_{2}$ and particulate matter emissions due to the full pay load and higher efficiency of trains, and reduce inner city noise and congestion. The scheme may present disadvantages such as added cost due to the 'double handling' of freight, and it may take longer to transport the freight using a multimodal system than via direct road transport, so it may not be suitable for time-sensitive goods.

The system proposed is not envisaged to handle heavy haul rail freight operations on the Tyne and Wear metro network. Instead it will focus on the transportation of small medium size parcels, low density high value goods and recyclable material. To address the technical aspect of rolling stock, the existing metro fleet should be redesigned to transport such freight. Hence all trains running on the Tyne and Wear metro network will behave like the current metro fleet for passengers.

To understand this study fully, there is a need to understand the reasons behind the dominance of road transport, and to evaluate the modal choices available to logistics companies. The feasibility of such a system relies on its ability to compete with other transport modes, and its capability to overcome problems such as a lack of 'door-todoor' service and the need for investment.

The remainder of the paper is as follows: Sect. 2 is a comprehensive review of the current situation regarding the transportation of freight, both in the UK and globally. It includes case studies relevant to the discussion, along with a review of the benefits and weaknesses presented by each mode of transport, in an attempt to determine the reasoning behind the overwhelming choice of road to transport freight. Section 3 outlines the use of software named COBALT, to assign a monetary value to the reduction of accidents through removal of vehicles from the roads surrounding Newcastle. Section 4 presents the results from this modelling, with Sect. 5 presenting observations about the implementation of such a system, and Sect. 6 coming to a conclusion on the study as a whole. Section 7 then outlines any further work that is recommended on the subject.

\section{Current Transport Situation}

\subsection{The Fall of Rail Freight}

According to Headicar [31], "freight haulage by road overtook the volume carried by rail in 1995", and although it has seen a resurgence in recent years, it has not regained its modal share. When one looks at the scale of goods transportation by road, Headicar also tells us that "just under one-fifth of all road vehicle miles are represented by freight movements". It is therefore clear that the transportation of goods by road contributes largely to the volume of traffic on the roads, and as a result also contributes to congestion, harmful emissions and noise pollution. Marinov [35] suggests that the reason for the surge in popularity of road transport was the beginning of mass production in the late twentieth Century; rather than taking directly from the market share of freight by rail, road took on the need for increased volumes of transportation.

Woodburn [63] reports that returning to the volumes carried by rail at the height of the industry's dominance would be a very difficult task, due to the many changes in transport infrastructure that have occurred in recent years. The Institute of Mechanical Engineers has predicted that by 2030 there will have been a $60 \%$ increase in the volumes of freight being carried and an increase of $114 \%$ in tonnekilometres [33]. It goes on to say that "this growth cannot be met by the current infrastructure available", concluding that "we are outgrowing our multi-functional network". If we are to achieve the targets set out by the most recent European Commission White Paper that "30\% of road freight over $300 \mathrm{~km}$ should shift to other modes such as rail or waterborne transport by 2030, and more than $50 \%$ by 2050", [8], the current rail network must undergo substantial amounts of renovation, requiring significant investment.

If such a modal shift was achieved, it would have the potential to have a significant impact on many aspects of the UK's transport network. Just some of the statistics [33] regarding freight transportation by rail include:

- $\mathrm{CO}_{2}$ emissions from rail freight are nearly ten times lower than those from HGVs. 
- UK businesses lose $£ 10$ billon per annum from congestion. If this could be reduced, it would have a significant impact on the economy.

- 1 gallon of fuel moves 1 tonne of goods 246 miles by rail, but just 88 miles by road.

- If all freight moved in 2004 had been carried by rail, it would have produced 3.6 million tonnes of $\mathrm{CO}_{2}$. This is a $90 \%$ reduction against the actual emissions of freight transportation in 2004.

These figures highlight the inefficiencies of transporting freight by road, and demonstrate some of the benefits presented by rail transport. It is clear, therefore, that a modal shift to rail must be considered.

One of the significant drawbacks of freight by rail is its lack of door-to-door capability. It rarely has the ability to transport directly to the customer and must therefore rely on another mode of transport to deliver the last leg of the journey. It is clear, therefore, that the development of road-based transport cannot cease if there is a modal shift to rail. They must continue to develop together, as rail will still need to rely on a separate mode of transport to complete the journey.

\subsection{Conventionally Powered Vehicles}

HGVs, or 'heavy goods vehicles', are now the most common way of transporting freight throughout the UK and Europe. Figures show [17, 18] that the freight industry has been steadily in decline since 1999, with fewer enterprises and new licenses being issued. However, in recent years, a greater proportion of heavier articulated goods vehicles have been licensed. In 2000, $26 \%$ of all articulated goods vehicles licensed had the capacity to carry over 40 tonnes. By 2010, this figure had risen to $72 \%[17,18]$.

HGVs have a certain number of advantages. They have the ability to transport goods directly from the source to the customer, with relative ease. This is a source of great convenience, as hauliers do not need to collaborate with other businesses to ensure that the product arrives with the customer. The design of HGVs also makes them well suited for use in either intermodal or multimodal systems. HGVs can be fitted with TEUs (twenty-foot equivalent units), amongst other types of container, and with the right equipment, these can be used interchangeably between rail, road, and sea transport.

However, there are also numerous limitations imposed on HGVs when transporting freight. Regulatory boards limit the weight of the vehicle to 44 tonnes and limit the size of the trailer that can be carried [32]. HGVs can therefore carry significantly less in a single journey than when compared to rail or sea.

HGVs also have speed restrictions; vehicles carrying more than 7.5 tonnes cannot travel faster than $60 \mathrm{mph}$ on dual carriageways [30, 43]. This is slower than the main flow of traffic and limits the speed with which goods can be delivered.

There is evidence to suggest that HGVs can have a negative effect on inner city congestion. Due to their larger length, HGVs can take up the same amount of space that would otherwise be occupied by four passenger cars [47]. Large trucks also struggle to navigate complex road networks such as those often present in cities, as it takes more time for such vehicles to turn right at junctions and travel around roundabouts [47].

Perhaps one of the most potent issues in the twenty-first Century is that of emissions from vehicles. It is widely accepted that HGVs are not 'environmentally friendly', and that they contribute a disproportionate amount of emissions to the atmosphere. A recent study suggested that HGVs contribute $21 \%$ of all $\mathrm{CO}_{2}$ emissions from surface transport, along with $28 \%$ of $\mathrm{NO}_{\mathrm{X}}$ and $16 \%$ of particulate matter emissions. This is despite HGVs only accounting for $1.5 \%$ of all road vehicles [20].

The UK Government has set a target of decreasing the UK's greenhouse gas emissions by $80 \%$, from a baseline figure of that in 1990, by 2050 [14]. If emissions from transport are not cut, it may be that this target becomes impossible to achieve.

LGVs, or 'Light Goods Vehicles', are also rising in popularity, with an increase of $35 \%$ between 2000 and 2010 [32]. Whilst not all LGVs are used for freight transportation, figures suggest that in 2008, $21 \%$ of all LGVs registered were used for 'collection or delivery of goods' [17, 18].

LGVs are defined as a vehicle whose gross weight does not exceed 3.5 tonnes and have similar advantages to those of the HGV. They have very good door-to-door capabilities, perhaps even more so than their larger counterparts due to their smaller size. They are also readily available on the market, for a much smaller investment than HGVs, allowing small businesses, a doorway into transporting their own freight.

LGVs suffer from many of the same limitations that apply to HGVs. They are restricted to $60 \mathrm{mph}$ on dual carriageways [30], causing many of the same problems regarding speed of transportation and traffic flow as discussed earlier. LGVs are not capable of intermodal transport using a large standardised container, however, can still be involved in a multimodal transport system. The high emissions from LGVs are a cause for concern; a study into $\mathrm{CO}_{2}$ emissions from $\mathrm{LGVs}$ found that whilst emissions from passenger cars decreased by $3 \%$ in a two-year period, emissions of $\mathrm{CO}_{2}$ from $\mathrm{LGVs}$ rose by $22 \%$ in the same period [2]. This is harmful to both the environment, and the Government targets for cutting emissions. 


\subsection{Intermodal Transport}

According to Reis [48], the European Union has realised that the growth of road transport is unsustainable, and therefore, they heavily support the use of intermodal transport. Bontekoning [6] demonstrates that due to the emerging nature of research on the subject, there is no one definition of intermodal transport; indeed each of the authors of the 92 publications reviewed during the report in question used "a definition that reflects the scope of their research", as one would expect. However, most sources tend to agree somewhat with the definition presented by the UNECE in the 2009 glossary for transport statistics: "multimodal transport of goods, in one and the same intermodal transport unit by successive modes of transport without handling of the goods themselves when changing mode" [62]. A proper definition is paramount to the development of a system and allows for greater progression in that field.

Currently, however, there are relatively few systems that are utilizing intermodal transport. Reis [48] tells us that at an EU level, $75 \%$ of freight is transported via road with just $5 \%$ of this transport being classed as intermodal. The paper then goes on to explain the barriers that face intermodal transport; it is complex to produce and relies on integration of disparate transport networks, and the regulatory framework is often inadequate.

Another issue raised by numerous authors is the increased drayage that can be introduced into an intermodal system. If we take an example of using rail to transport freight, the goods must arrive at the rail station and subsequently be transported to their final destination at the end of the rail journey. These initial and final transportation legs are known as drayage movements. Bontekoning [6] shows that "despite the relatively short distance of the truck movement compared to the line haul, drayage accounts for between 25 and $40 \%$ of origin to destination expenses". These high drayage costs can have a significant impact on the profitability of an intermodal system. A paper from Craig [9] determined that "for the overall intermodal shipment to be more efficient than truckload, the length of the linehaul must be long enough to offset the lower efficiency of drayage". Reversed, that is to say the length of the drayage must be short enough for the system to reap the benefits of the higher efficiency of rail. The results from this study concluded that the efficiency and benefits from using intermodal transport must be evaluated on a case-by-case basis.

One way to reduce the inefficiencies added by drayage distances would be to use zero-emission vehicles such as electric vans or bicycles to transport the freight to and from the rail terminals. This would allow for low emissions in the initial and final drayage legs; however, relatively close proximity to the station would be necessary.

\subsection{Electric Freight Transportation}

Electric vehicles are much more environmentally friendly than their petrol or diesel powered counterparts. Deemed 'ultra-low emission vehicles' (ULEVs) by the government, each must release below a specified value of greenhouse gases during operation.

Methods of urban freight distribution have been centred on the use of conventionally powered HGVs and LGVs for many years, with little in the way of a shift towards a more environmentally conscious mode of transportation. Indeed until recently, this image was mirrored across the transport market as a whole; in 2009, less than $0.1 \%$ of cars registered in the UK were electric [28]. However, more recently there has been a large increase in the demand for such vehicles [51, 52]. In 2014, the sales of ULEVs increased fourfold on the value from the previous year, from 3586 to 14,498 [55]. Such a rise in demand could be attributed to many factors: an increase in the number of models available on the market, a rise in the accessibility of charging points, or the availability of grants to purchase vehicles. However, the underlying motives behind the purchase of an ULEV are the desire for transport that produces less $\mathrm{CO}_{2}$ that increases air quality, and that leaves less of a long-term impact on the environment [54]. Why then, has this jump in sales of electric vehicles not been mirrored in freight transportation?

A report published by PTEG [45] states that there has been "no significant shift towards low emissions vehicles in the LGV market", with natural gas/electric powered vehicles accounting for less than $0.1 \%$ of vans registered in 2013. Electric HGVs are available on the market; however, they have a range of around 100 miles, which is not suitable for long freight journeys. During initial research, several electric LGVs were sourced, all of which had a similar range to that of the electric HGV, around 100 miles [44]. This significantly lessens the potential for the use of electric vehicles for freight transportation, which often requires long journeys. It is clear, therefore, that it will be some time before electric vehicles are able to compete as a stand-alone method of freight transportation.

This is not to say that electric vehicles do not have their place in goods transportation. When combined with another mode of transport, or used to perform 'last mile' deliveries, small electric vehicles allow for vast reductions in $\mathrm{CO}_{2}$ emissions per package.

It can also be said that electric vehicles are quieter than conventionally powered transport. Whilst running, they are virtually silent, and even hybrid vehicles will only use the internal combustion engine for a small part of the journey. The introduction of more electric vehicles could significantly reduce noise pollution in city centres.

The government is keen for people to make the transition to Ultra-Low Emission Vehicles, and is therefore 
offering grants, to make the vehicles more accessible. A grant of up to $£ 5000$ is available for this type of vehicle, until 50,000 grants have been issued, or before the beginning of 2017, whichever comes first [41, 42].

\subsection{Bicycle Couriers}

Bicycle couriers are a mode of freight transportation that has been increasing in popularity in recent years, and many cities have at least one courier service operating in their centre. A bicycle is a zero-emission vehicle that either relies solely on power provided by the rider, or is electrically assisted through the use of a small motor. When used as a method of freight transportation, it has the ability to help reduce congestion and to improve both noise and air pollution in city centres.

A study funded by the Intelligent Energy Europe Programme of the European Union [27] suggests that "51\% of all motorized trips in EU cities that involve the transportation of goods could be shifted to cargo bikes". This sort of modal shift would have a significant impact in city centres, particularly in cities that suffer from high congestion levels.

Bicycles have the ability to use both roadways and cycle paths, which means that in many cases, it can be faster to travel around a city centre using a bicycle than using a motorized vehicle such as a car or HGV. If cycle logistics were to become a large-scale operation, investment in 'cycle highways' would be necessary. Indeed there has been a plan proposed for two cycle superhighways to be built in and around the capital city, London, in an attempt to persuade more of the general public to cycle [58]. These could also be used for the transportation of freight, allowing for fast and carbon neutral delivery directly to the heart of London.

Another major benefit of using cycle couriers is that the bicycles would not be susceptible to congestion charges, which are present in some cities throughout the UK. This charge must be absorbed by the haulage company in some way, and it is therefore likely that the cost will be transferred to the customer.

However, by design, bicycle courier services cannot carry the same volumes of freight that most other forms of transportation can, simply due to the fact that cycling with large bulky goods would become impractical. A cycle courier, 'Outspoken! Delivery', based in Cambridge and Glasgow can transport up to $250 \mathrm{~kg}$ of goods using their 'Maximus Bikes', which are used "almost exclusively in the city centre for last mile logistics" [16]. This is clearly not in the same range as the 44 tonnes that a $\mathrm{HGV}$ is capable of carrying, however, may be sufficient for many 'last mile' applications.

\subsection{Case Study-GNewt Cargo}

A London-based courier service, GNewt Cargo evolved from the desire to revolutionise inner city logistics in one of the most congested and polluted cities in the UK. When the business was formed in 2009, cargo cycles were their main form of transportation; however, as the business has grown, more and more electric vehicles have been brought into service. The company is thriving; every year since its formation, it has grown by at least $50 \%$, and in 2014, it doubled its electric vehicle fleet. Now, up to 17,000 parcels are delivered daily, and as all vehicles are $100 \%$ zero emission at tailpipe, huge savings are made in $\mathrm{CO}_{2}$ emissions [50].

Using a combination of electrically assisted cargo tricycles and electric vans, along with an urban micro-consolidation centre to increase the loading factor of each vehicle, GNewt Cargo has produced a $54 \%$ fall in total $\mathrm{CO}_{2}$ emissions per parcel carried. In the centre of London itself, the reduction was $83 \%$ per parcel, demonstrating that such systems carry huge potential [7].

\subsection{Urban Consolidation Centres}

Rooijen [49] defines an Urban Consolidation Centre (UCC) as "an initiative which uses a facility, in which flows from outside the city are consolidated with the objective to bundle inner-city transportation activities". By loading a greater number of goods onto each vehicle, the total number of trips into a city centre can be vastly reduced, which is one of the defining attributes of the UCC. A major cause of inefficiency in HGV freight distribution is the low volumes carried in the last mile, which the use of an UCC could help to stop. Using an UCC to combine part-loads could also vastly reduce the total road miles travelled, which would have a significant impact on inner city congestion.

Regarding the use of bicycle couriers, Schliwa [50] concludes that "Urban Consolidation Centres were identified to be the major complementary infrastructure to enable cycle logistics operators to keep the length of the journeys, and hence the delivery time, short", and even refers to them as a "necessary precondition" to the success of a bicycle courier service. It is therefore clear that for a system which chooses to use a cycle courier for last mile transportation, the use of an UCC is crucial to whether the scheme is a success or failure.

Allen et al. [3] has identified, however, that in comparison to other EU countries such as Germany and Italy, the UK is poor at implementing trials of UCCs. In the UK, "two-thirds of UCCs identified did not proceed beyond a research project or feasibility study", compared to other EU countries where "the vast majority of UCC studies proceeded to either a trial or a fully operational scheme". 
The paper then goes on to specify that the lack of trials in the UK is caused by a lack of funding; there is money available for research projects however funds are not sufficient to invest in numerous trial schemes.

Allen et al. [3] comes to the conclusion that "UCCs have the ability to improve the efficiency of freight transport operations and thereby reduce the congestion and environmental impacts of this activity". The paper also identifies that UCCs allow the opportunity for zero-emission vehicles to carry goods the last mile into city centres, thus further increasing the efficiency of the operation.

\subsection{Short Distance Light Rail}

Many cities in the UK have an existing light rail network, whether it is a metro-based system, or a network of trams, and there is increasing scope to use these systems for the transportation of freight in city centres. As opposed to the heavy rail freight industry, which would need investment, in many cases transporting goods via light rail would simply utilize the existing infrastructure. Often little alteration would be needed, with current platforms and train carriages sufficing, albeit in a modified form. A recent study of urban freight distribution [53] suggests that the use of easily portable, standardized containers such as the 'Bento Box' would be suitable for use on light rail systems which had simply had the grab poles and seats removed. Trains that were no longer fit for passenger use could be repurposed; indeed there is a plan to upgrade the existing metro fleet in Newcastle, with the new fleet beginning operation in 2025 [37]. The old rolling stock could be modified and used in freight transportation, both reducing the need for investment and 'recycling' the unwanted carriages.

There are many different forms of light rail system in operation; however, this paper looks at the one operated by Nexus throughout Newcastle and the surrounding area. The Tyne and Wear Metro fleet, despite having been in operation since the opening of the network in the 1980s, is in the top third in terms of overall energy efficiency per train-kilometre during operation [37]. There is an initiative in place to generate much of the electricity used by the Metro using renewable sources such as wind turbines and solar panels, with an aim to become a "100\% green energy transport network" in the future. It is estimated that $10-15 \%$ of this energy could be generated at Metro stations [37]. There are no data available in the public domain regarding the actual value of Metro energy efficiency, and for a fair comparison with other modes such data would need to be analysed. The same can be said when looking at emissions of nitrous oxides and other harmful pollutants; the potential benefits cannot be properly evaluated without access to emissions data.

Using light rail would have a significant impact on the congestion in city centres. Section 3.5 looks in detail at the number of vehicles that could be removed from the roads around Newcastle city centre if the Metro network was used to transport just a fraction of goods from local businesses. Reducing the number of HGVs on the road would have a significant effect on the safety of both pedestrians and motorists. A study [45] suggests that not only are HGVs involved in a disproportionate number of both pedestrian and cyclist fatalities, but an accident involving a cyclist and a HGV is over twelve times more likely to be fatal than a cyclist-car collision. Such statistics show that a decrease in HGV numbers would vastly improve the conditions for those regularly travelling through inner city roadways on bicycles and by foot.

Metro systems are, however, not capable of providing 'last mile' transportation. In the case of Newcastle, the goods would need to be brought from an underground station to street level, to then be distributed to the final destination via another mode of transport. This would add complication and potentially expense to the system and would have a significant impact on the transportation of time-sensitive goods.

Concerns have also been raised regarding the potential for disruption to passenger services if light rail was used to carry freight. In many urban transportation systems, trains run at the minimum specified headway, meaning that if freight trains were to be introduced, the existing passenger timetable would have to be altered. It has been suggested that the Tyne and Wear Metro system is operating at very low efficiency in terms of the number of trains running, which suggests that there is scope for the introduction of freight rail in-between passenger services.

\subsection{Case Study: Monoprix}

As part of the Global Report on Human Settlements 2013, a case study was prepared on the transportation of commercial goods by Dablanc [13]. As a part of this, an indepth evaluation of an intermodal transport system adopted by Monoprix was performed. Monoprix is a large chain of supermarket stores, with more than 300 urban supermarkets throughout France. In November 2007, the company began running a train service carrying goods for the supermarket from a warehouse in the suburbs of the city to Bercy rail station. From there on, Compressed Natural Gas (CNG) vehicles were used to perform last mile operations. In this manner, 65 stores in Paris are supplied, along with 25 stores in other regions.

This method of goods transportation has achieved significant environmental benefits upon the previous method. According to Dablanc [13], there was a reduction of 700,000 lorry miles travelled, along with a $36 \%$ decrease in particulates emitted, a $56 \%$ decrease of nitrous oxides and a drop of $47 \%$ in $\mathrm{CO}_{2}$ emissions, with 410 tonnes less of $\mathrm{CO}_{2}$ emitted per annum. 
Such impressive figures speak for themselves; however, as with anything, there are limitations to the success. Dablanc also reports much negative feedback regarding noise emissions. Monoprix opted to use passenger rail facilities at off peak times such as overnight, however residents in the surrounding area complained of increased noise due to the late night running of trains.

The matter of the funding and the cost of the system must also be raised. The municipality invested $€ 11$ million to allow the scheme to function; however, there is no charge to Monoprix for using the system, so this money will not be paid back. The cost per pallet was also increased by $26 \%$, an undesirable side effect that may be transferred directly to customers [13]. A suggestion from Dablanc was to run two trains each night, allowing for "better use of the employees", and "a more optimal use of the facility".

\subsection{Lessons Learnt}

When reviewing the data regarding making modal shifts and the huge variety of other modes of transport available for movement of freight, it is surprising that more businesses have not opted to make a transfer. Huge savings in carbon dioxide emissions can be achieved by a switch to any mode of transport other than conventionally powered vehicles, which are the least efficient yet the most commonly used.

However, it is clear that some modes are more suited to certain applications than others. It would not be possible to use a cycle courier to transport goods from one end of the country to the other, any more than it would be appropriate to use a freight train to deliver goods the last mile. A combination of these different modes of transport seems to be the best approach, with a multimodal system allowing for the combination of the greater efficiency of freight by rail with the zero emissions of cycle couriers or electric vans.

It is also clear that the optimum system for each city must be determined on a case-by-case basis. Each city is different, and what may work in one place would not in another. A scheme that would function using an underground system would need to be adapted for use with trams. There is not a universal template that can be applied to all cities, and thus, it was decided that the potential scheme in Newcastle should be further analysed using modelling software, to ascertain the benefits that are possible.

\section{Analysis of Potential System Using COBALT}

\subsection{Review of Software}

There are many software packages which would have been suitable for the analysis of a modal shift to light rail in Newcastle, which were initially considered for the investigation of the scheme. Xpress MP is a linear programming software, allowing many different scenarios to be mathematically modelled. A basic model was developed, which would have allowed the user to input of the cost per unit volume of various different modes of transport, determining the most cost effective over a set distance. This model could then have been repeated, using emissions data instead of cost, to determine which mode of transport would be the most environmentally friendly over a distance. This is recommended in the future, to gather more information about the potential scheme. It was not used due to issues with operating systems, however, is available for free download for members of a university.

Other modelling systems were also considered, such as Arena and SIMUL8, which are both classified as event-based simulation software packages. These have been successfully used in studies of similar systems in the past, with Motraghi \& Marinov [36] using Arena to analyse an inner city freight by rail scheme for Newcastle upon Tyne, and Abbott \& Marinov [1] studying a high-speed railway system through use of the same software. This highlights the benefits of using event-based simulation; it can be adapted for many different purposes and used to analyse many different systems.

Specific transport modelling software is also available which allows users to analyse railway systems. OpenTrack is a specific rail modelling system, allowing for analysis of many different modes of transport including high-speed rail, metro systems, heavy haul freight and other trackbased modes. This would also be suitable for a study to determine where would be the optimum placement of a dedicated freight train in a passenger timetable. Railsys has been successfully used in several papers to analyse a transport timetable, which would be a useful addition to the work presented in this report. Chen and Han [65] used OpenTrack in an analysis of the Nanjing-Shanghai highspeed railway, to study the carrying capacity of the system. Such a model could be adapted to suit the potential Newcastle scheme.

After a review of the various software packages available to analyse potential modal shift, COBALT was chosen for use in this study. As shown in the Monoprix case study, there is often an investment required to allow such a system to begin functioning; an UCC may need to be developed, or trains may need to be repurposed for the transportation of freight. This cost is often borne by the local authority and short of charging for use of the system; there is little way that these funds can be repaid. COBALT was chosen to demonstrate that there is a distinct monetary benefit to the implementation of such a scheme in Newcastle. Whilst initial funding may be needed, it may be the case that the cost of this investment is reaped back in the savings from accidents and notably the reduction in the use of emergency services to deal with these. 


\subsection{WebTAG-COBALT}

COBALT, or COst and benefit to accidents-light touch, is an Excel-based software developed by the Department for Transport. It is an analysis tool and determines the impact on accidents as part of an economic appraisal for a road scheme [59]. Data regarding each section of road and each junction that would be affected by the scheme are required, such as Annual Average Daily Traffic data, local accident rates, speed limit and link length. The user calculates data regarding the 'With Scheme Flows', containing information about the traffic flows under the proposed scheme. A parameter file is made available by the DfT, containing information pertinent to the financial implications of accidents such as 'casualty rates' and 'cost per casualty'. When the analysis is run, this assigns a monetary value to the number of accidents that would be prevented by the implementation of a scheme. Below is an example input file, provided by DfT, to demonstrate some of the necessary data (Fig. 1).
This is a very useful analysis tool, as not only does it force the user to perform an in-depth study of the area which would be affected; it has the ability to calculate the economic benefits to society should the scheme be implemented.

Once the relevant data are obtained and analysis is performed, COBALT presents an output file, with detailed analysis on a year-by-year basis regarding the financial impact of the system. It will determine if the number of road accidents would increase, remain unchanged or decrease, and the severity of accidents that could be prevented. An example (condensed) output file is shown below in Fig. 2.

\subsection{Killingworth}

Inspired by the successes of the case studies presented earlier and the desire to reduce noise and carbon emissions in the city centre, this report aims to determine whether a multimodal system utilizing the Tyne and Wear Metro

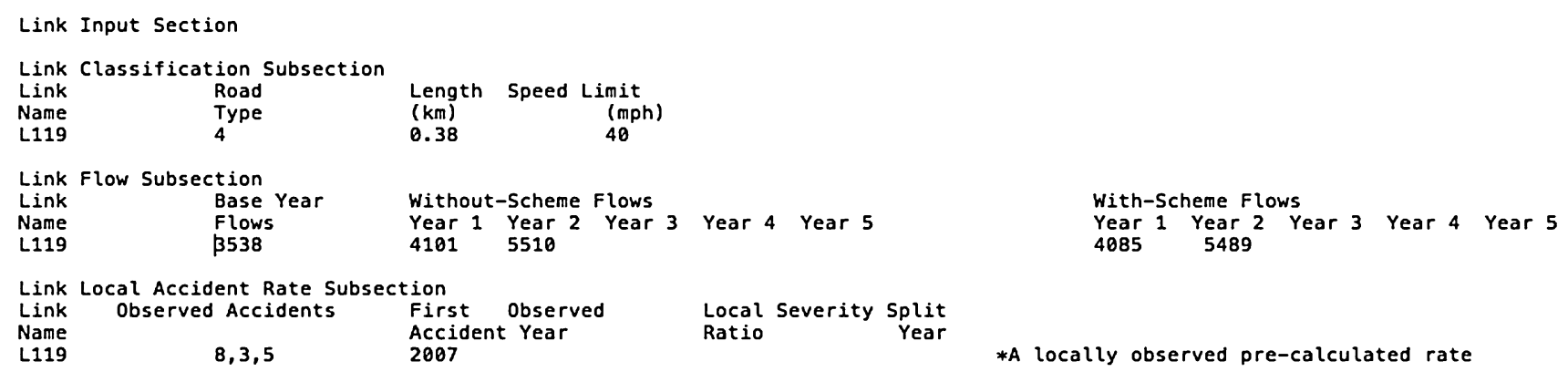

Fig. 1 Example COBALT input file [59]

Fig. 2 Example COBALT output file [59]

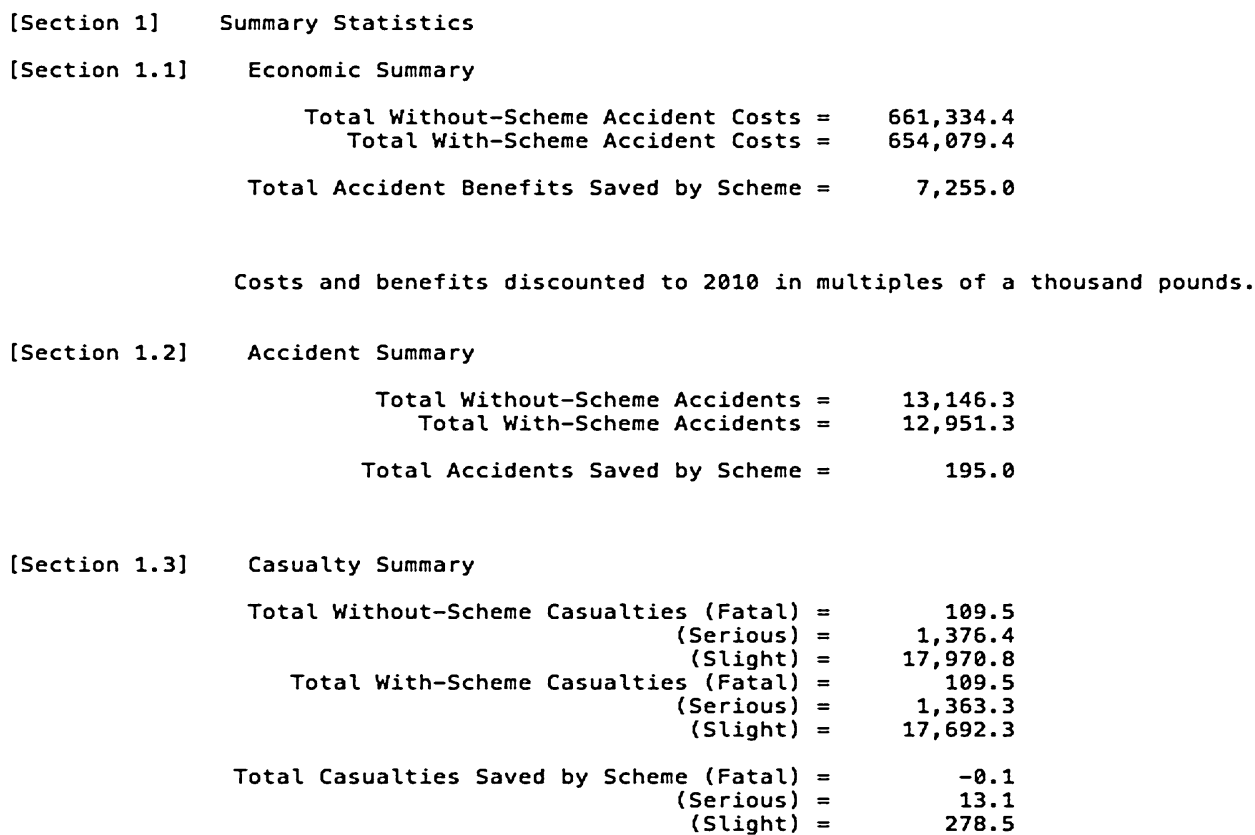




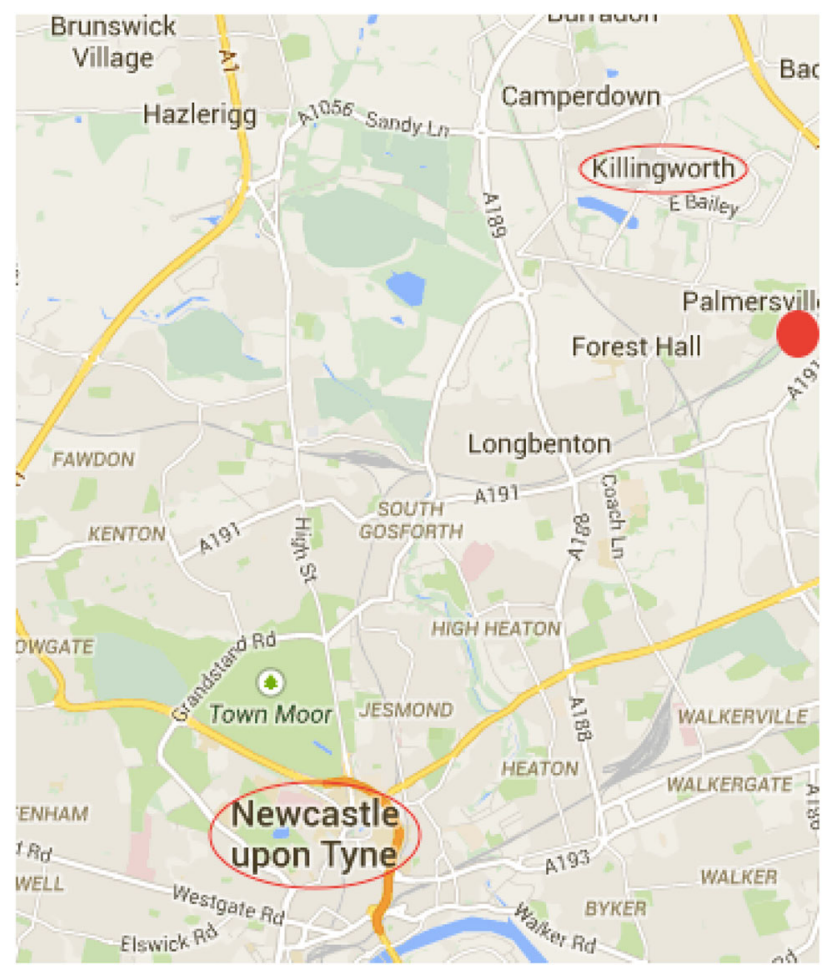

Fig. 3 Location of Killingworth [29]

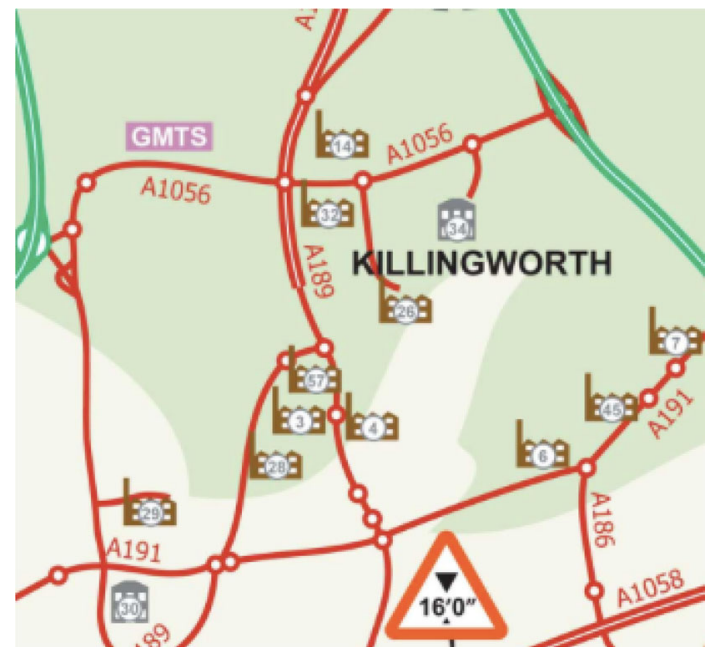

Fig. 4 Businesses around Killingworth [29]

system, combined with electric vehicles and bicycle couriers, would be feasible and beneficial for Newcastle upon Tyne.

The suburb of Killingworth to the north of the city centre was chosen as a study, due to the large numbers of businesses located in a small radius (Fig. 3). Figure 4 is a schematic of the businesses located in and around Killingworth.

The Tyne and Wear Freight Partnership maps were developed to allow logistics companies to determine the

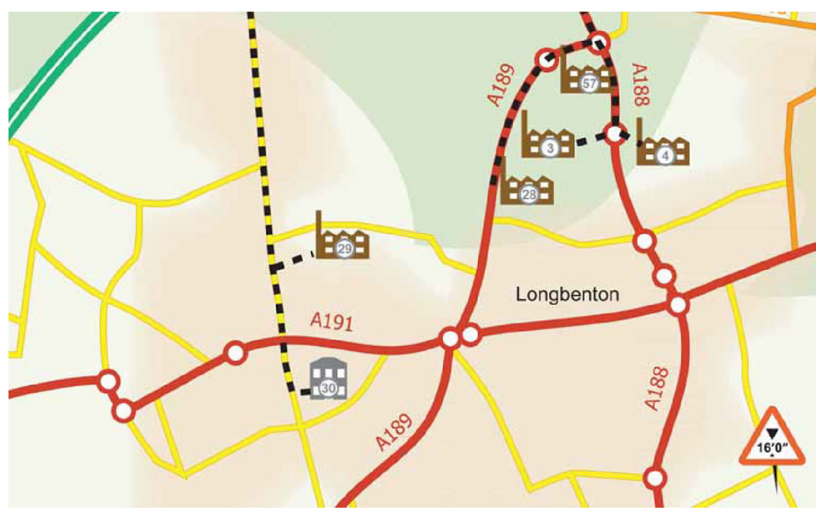

Fig. 5 TWFP map [61]

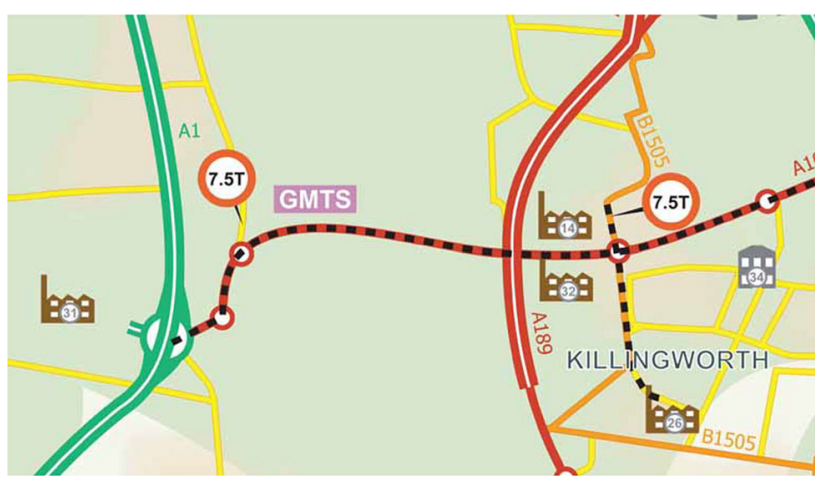

Fig. 6 TWFP map [61]

optimum route to access freight destinations within Tyne and Wear [61]. These maps have therefore been used to find the route that would be taken by a vehicle making a delivery to the city centre. Examples of these maps are shown in Figs. 5 and 6, with the dashed line being the preferred route for freight to travel by.

By determining the route taken by each business, it gives a clear picture of how the surrounding roads would be affected if a number of vehicles were taken from the roads. All businesses were directed to the city centre via either the A1, or the A19, two of the main roads that lead into Newcastle.

The data taken from the Tyne and Wear Freight Maps allowed the 'link length' to be found and provided a starting place from which other data such as speed limit and accident rate could be found. This then helped to build the 'Link Input Subsection' of the COBALT file.

\subsection{Metro Links}

The closest Metro station, Palmersville, can be seen in Fig. 3, in red. All of the businesses in the study were chosen as they are within a ten-minute road journey of Palmersville. Trains run regularly from this station to 
Table 1 Palmersville to monument metro timetable [38-40]

\begin{tabular}{lllll}
\hline Depart & Arrive & Changes & Time & Headway \\
\hline $20: 25$ & $20: 41$ & 0 & $00: 16$ & $00: 13$ \\
$20: 38$ & $21: 14$ & 0 & $00: 36$ & $00: 02$ \\
$20: 40$ & $20: 56$ & 0 & $00: 16$ & $00: 13$ \\
$20: 53$ & $21: 29$ & 0 & $00: 36$ & $00: 02$ \\
$20: 55$ & $21: 11$ & 0 & $00: 16$ & $00: 13$ \\
$21: 08$ & $21: 44$ & 0 & $00: 36$ & N/A \\
\hline
\end{tabular}

Monument in the city centre, beginning operation at 0550 and ceasing at 2353. Journey time varies; the fastest train takes 16 min to arrive at Monument Metro station and journey length varies between 16 and $36 \mathrm{~min}$, depending on which direction the train takes towards the city centre.

Table 1 shows a section of the Metro timetable running between Palmersville and Monument, [38-40], with the calculated headway between trains. This value varies; however, a headway of 13 min shows that there is the potential to run a dedicated freight service between passenger trains. Arvidsson and Browne [4] put forward the theory that there are five main barriers to the success of any urban freight by rail scheme, the first of which is that "the scheme must not interfere with public traffic". The primary role of any urban rail system is the transportation of personnel, not freight, and the system must be treated as such. Clearly passenger services must have priority; however, by studying Metro timetables in depth, we can find the optimum time to run freight services, with little or no disruption to the every-day traveller.

Following discussions with Nexus, it has become apparent that there is a link connecting Manors Metro station and Jesmond Metro station, which is just over $1 \mathrm{~km}$ in length. This link can be seen in Fig. 7, in red. These two stations are not connected for every-day use; however, this connection is used to allow a faster return to the depot late at night when services terminate. It is rare that this line is used during the day, and this would therefore allow more time to unload freight from trains, without needing to allow another metro carriage to use the line. In time, if the scheme was further developed, a distribution centre would be recommended, to improve the efficiency of the sorting and dispatch of goods to their final destination. This would also be the destination from which last mile couriers would depart into the city centre. It is less than $2 \mathrm{~km}$ from the optimum placement of a distribution centre along this track to Monument, which is a feasible distance for a cycle courier to travel.

\subsection{Distance Travelled by Road}

Many of the businesses in Killingworth are industrial estates or business parks, containing large numbers of individual business premises. There is also a large shopping centre in the village. Using a conservative estimate that $50 \%$ of businesses located at each site make just one journey each week into Newcastle city centre, along with a third of businesses from the shopping centre, it can be calculated that a total of $4485.48 \mathrm{~km}$ is travelled cumulatively each week, if return journeys are included. The breakdown of the journey for each business is shown in Table 2, which also gives a reference for the information regarding each business. Due to time constraints, online information was used; however, if the project was to be

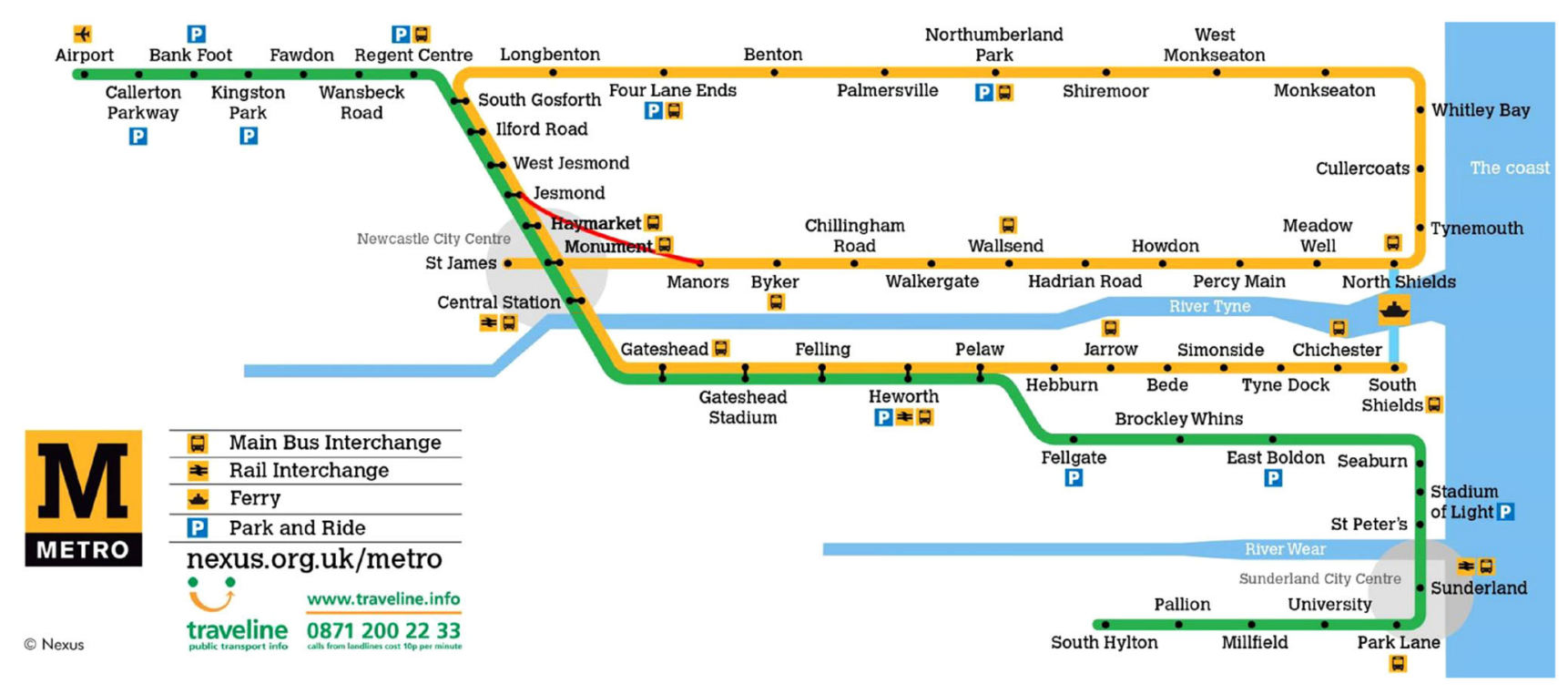

Fig. 7 Metro line linking Manors and Jesmond [38-40] 
Table 2 Calculation of road kilometres travelled by businesses surrounding Killingworth

\begin{tabular}{|c|c|c|c|c|c|c|}
\hline $\begin{array}{l}\text { No. on } \\
\text { TWFP map }\end{array}$ & Businesses & $\begin{array}{l}\text { Journey } \\
\text { length/km }\end{array}$ & $\begin{array}{l}\text { Vehicles removed } \\
\text { from road }\end{array}$ & $\begin{array}{l}\text { Distance travelled weekly } \\
\text { (one way)/km }\end{array}$ & $\begin{array}{l}\text { Distance travelled weekly } \\
\text { (return journey)/km }\end{array}$ & $\begin{array}{l}\text { Referenced } \\
\text { from }\end{array}$ \\
\hline 14 & 29 & 13.54 & 14.5 & 196.3 & 392.7 & [23-26] \\
\hline 32 & 10 & 13.54 & 5 & 67.7 & 135.4 & {$[11,12]$} \\
\hline 34 & 68 & 13.54 & 34 & 460.4 & 920.7 & [34] \\
\hline 26 & 7 & 14.54 & 3.5 & 50.9 & 101.8 & [64] \\
\hline 7 & 20 & 12.32 & 10 & 123.2 & 246.4 & {$[11,12]$} \\
\hline 45 & 75 & 12.62 & 37.5 & 473.3 & 946.5 & [23-26] \\
\hline 6 & 28 & 14.43 & 14 & 202.0 & 404.0 & [23-26] \\
\hline 28 & 57 & 15.19 & 28.5 & 432.9 & 865.8 & [23-26] \\
\hline 3 & 10 & 13.49 & 5 & 67.5 & 134.9 & [23-26] \\
\hline 4 & 25 & 13.49 & 12.5 & 168.6 & 337.3 & [46] \\
\hline Total & 329 & 136.7 & 164.5 & 2242.74 & 4485.48 & \\
\hline
\end{tabular}

continued, it would be beneficial to visit each site, to verify that the information found online was correct.

It is probable that this estimate of kilometres travelled is less than the actual value; the number of goods deliveries to the city centre will likely be higher than just half of businesses making one journey weekly; however, if there are still benefits to society with such a small number of journeys being considered, then the potential for expansion is much greater.

The calculation for reduction of road kilometres travelled is not one which was required for the COBALT input file; however, it was found to be useful as a reference number for comparison with other schemes. Case studies such as Monoprix and Tesco claim reductions of " 400,000 road kilometres weekly" [57] and "700,000 road miles per annum" [13], and it was felt that this form of analysis should be performed for the potential Newcastle scheme. When the number of road kilometres prevented is calculated on a yearly basis, the value is $233,245 \mathrm{~km}$, showing that such a reduction would be directly comparable with that achieved by Monoprix, albeit initially on a smaller scale. Should more businesses become involved, this number would rise greatly.

\subsection{Data Acquisition}

For the input file to be of value, accurate data regarding all aspects of each road link and junction were needed. This included values for the traffic flow through both junctions and links, along with the speed limit and length of each section of road. The local observed accident rate was also needed, and the 'with scheme' traffic flows for a number of years were predicted.

There were numerous sources used to find the data needed. All traffic flow data were taken from [19]. Using the interactive map provided (Fig. 8), the traffic data along a specific road could be determined. This method was also used for junction flows.

To calculate the number of vehicles that would be removed from the roads under the new system, the weekly reduction of vehicles from each business was taken and multiplied by 52 (the number of weeks in a year). The sum of all of the vehicles from the businesses using the same roads was then calculated, giving a total flow reduction for each section of road. This was then subtracted from the flows provided by the DfT to provide the 'With Scheme Flows' section.

The data regarding local accident rates were difficult to come by. The English road comparison safety website was closed on the 27th March 2015, as "equivalent information is now widely available online from other sources" [21]. A link was given to www.crashmap.co.uk, which provided an interactive map, with a marker at every point where an accident had occurred. Figure 9 shows an example of the data; each orange marker is a 'slight' accident, each red marker is 'serious' and black, not shown in the image, is a fatal accident. This was used to study each road link and junction in detail, and the number of accidents each year was manually counted. This means the data are accurate;

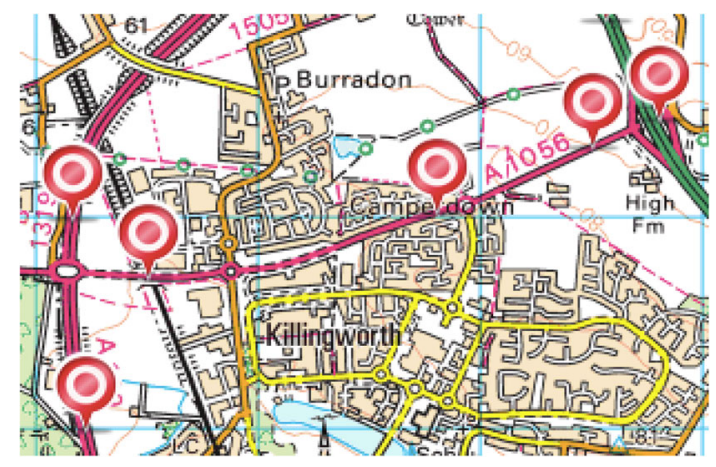

Fig. 8 Traffic count points Killingworth [59] 


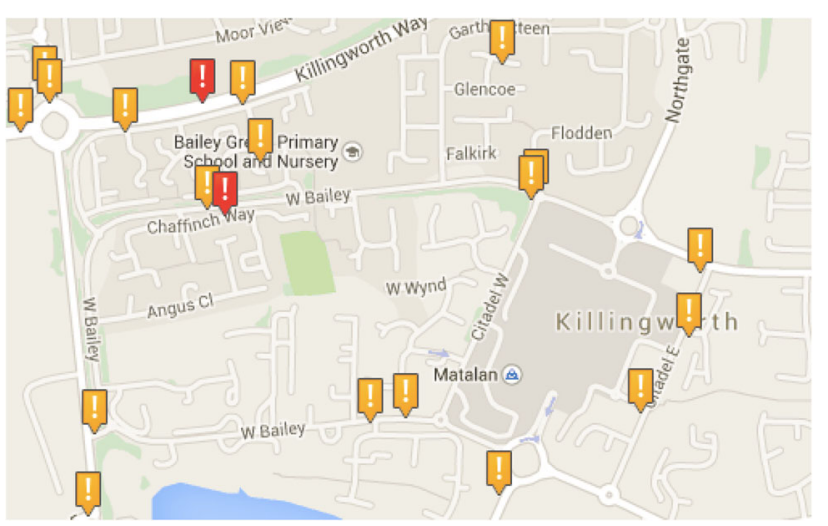

Fig. 9 Local accident data Killingworth [10]

however, for a larger system, this would be impractical. It is recommended that another source be found for local accident data.

Speed limit data were found using a combination of local knowledge and maps provided by Google. Again whilst this is accurate, it would be impractical for a system involving a larger number of roads, and a better method should be found if the analysis was repeated.

COBALT requires the user to define the length of time that is being studied, requiring the current year, a 'base year' with which to compare data, and then up to five specified dates in the future at which all information will be calculated. For this system, the current year is 2015, with a base year of 2012. Information regarding the scheme was calculated at three intervals: in 2020, 2023, and 2035. For this to occur, the file requires a prediction of traffic flow data for the future years. This was calculated using the "Automated Traffic Growth Calculator" [15], using the current traffic flow data provided by DfT. It has also been predicted that the scheme will remain the same for the first few years of operation up until 2020 , then would grow by a half by 2023, and then double by 2035 .

\subsection{Scenarios}

To increase the value of the model, it was decided to re-run the input file, under a number of different scenarios. This would allow the problem to be analysed in more depth, as when a greater number of solutions are studied, it is more likely that one of them will be relevant to the 'real-life' application.

Initially, the assumption was made that $50 \%$ of businesses make one weekly journey to the city centre. Through time, the validity of this assumption was questioned; what if the number was actually less, or indeed was much higher? The input files were varied accordingly, to allow for just $25 \%$ of businesses making a journey, all businesses making a journey, or all businesses making two trips into the city centre weekly.
The projected growth was also an assumption. As stated previously, it was predicted that the scheme would have grown by half by 2023 , which would involve 15 business parks using this form of freight transportation, and have doubled by 2035 , giving a total of 20 business parks participating in the scheme. This cannot be accurately predicted, so it was decided that the analysis should be run again, without the projected growth included. In other words, the number of businesses that use the Metro to transport freight would remain the same between 2017 and 2035. The desired outcome of this was to see how much of an effect the growth would have on accidents prevented.

There are 329 businesses contained in the 10 industrial estates and business parks around Killingworth. The model was adapted to determine the number of businesses that would need to be involved in the system to allow for a reduction in accidents and therefore the generation of significant monetary savings. This form of analysis would prove useful if the scheme was to be taken further; by determining the savings in cost with the introduction of more businesses, it would be possible to see how many companies would need to use the scheme to offset any initial investment cost.

This final form of analysis is not as accurate as the previous model, as there is no way to determine which out of the 329 businesses would be the first to join the scheme; hence, there is no way to know the exact roads affected. With this in mind, this version of the model was adapted just to look at four main road links, the A1056, A1, A167 and A189. Initial data were consulted, and it was found that seven out of ten of the business parks used these four links to reach the city centre. This simplification introduces an element of error into the system; however, it is necessary if the modelling is to occur.

\section{Results}

\subsection{Projected Growth Included}

This series of results involves the system evolving and more businesses joining over time. It was predicted that by 2020 , the scheme would have grown by half, and by 2035 , the scheme would have doubled in size. This growth would be facilitated through the remainder of the business parks in and around Killingworth becoming a part of the scheme, as just a handful was chosen for this study. In reality, some of the roads used by these new businesses would be different to those entered into the COBALT input file; however, as the TWFP maps directed all businesses to use the A19 or A1, the model will still be accurate to a level at which a basic analysis can be made.

It can be seen from Table 3 that even with a relatively small number of businesses making a modal shift, the 
Table 3 Data with projected growth

\begin{tabular}{llllll}
\hline Businesses involved & $\begin{array}{l}\text { Money saved } \\
\text { by scheme }\end{array}$ & $\begin{array}{l}\text { Accidents saved } \\
\text { by scheme }\end{array}$ & \multicolumn{2}{l}{ Casualties } & \\
\cline { 5 - 6 } & & & Fatal & Serious & Slight \\
\hline $25 \%$ make 1 trip & $£ 50,426.00$ & 994.2 & 10.7 & 107.7 & 1398.9 \\
$50 \%$ make 1 trip & $£ 94,308.40$ & 1805.7 & 21.1 & 205.2 & 2543.7 \\
$100 \%$ make 1 trip & $£ 189,588.00$ & 3549.7 & 43.8 & 414.4 & 4985.0 \\
$100 \%$ make 2 trips & $£ 277,238.50$ & 4976.9 & 68.6 & 618.3 & 6983.8 \\
\hline
\end{tabular}

initial savings are high. If just $25 \%$ of businesses made 1 trip weekly, which relates to around 80 separate businesses becoming involved in the scheme, a reduction in flow of 4732 vehicles per annum would be achieved. Due to the predicted growth of the scheme, by 2035 , the end of the time period specified in COBALT, this number would have risen to 9464. This reduction in flow contributed to the reduction in road accidents, and therefore, the increase in monetary savings which can be seen between the 'growth' and 'no growth' systems. This demonstrates that there is a potential for such a system to benefit the local authority; a very large reduction in vehicles on the road could be achieved if all of the businesses in Killingworth used the Metro to transport their freight twice a week, rather than driving a conventionally powered vehicle into the city centre. This would not only have an effect on casualties and money saved, but would cut $\mathrm{CO}_{2}$ emissions, noise pollution and particulate matter emissions.

It should be noted that this calculation of flow reduction is including the return journey, as using the Metro to transport freight would prevent a vehicle from both travelling into the city centre and then returning to the business.

\subsection{No Growth of Scheme}

These results do not include the growth that is predicted. The reduction of vehicles that would be achieved in the first year of the scheme remains the same through to 2035 . This allows for analysis of the system, even if the predicted growth was found to be unrealistic.

Table 4 shows that the projected growth of the system has an effect on the monetary gain from the scheme. This is to be expected; if the scheme does not grow, then the number of vehicles removed from the roads remains the same, thus the reduction in accidents is less. Savings are still significant, but may not be large enough to match the initial investment, depending on the scale of finance needed. However, the greater the number of businesses involved in the scheme, the smaller the gap between the growth and no growth schemes becomes relative to the overall monetary savings. For example, the difference in money saved if just $25 \%$ of businesses make 1 trip is $£ 16,481$, which as a fraction of overall savings without projected growth is just under a half. When all 329 businesses use the metro instead of 2 trips weekly, the difference between the growth and no growth schemes is $£ 36,322$, which as a fraction of the no growth scheme is around 0.15. This can clearly be seen in Fig. 10; as more businesses become involved in the scheme, the projected growth makes less difference as the overall monetary savings become larger.

\subsection{Savings for Both Schemes}

This is a comparison of the savings for both the scheme with projected growth and without. It can be seen that the relationship between the two is not a set value, nor is it a set percentage of total savings. Given that the scheme was initially set to double by 2035 , it would be expected that this would have a large effect on the monetary savings of the scheme; however, this is not the case.

There is a difference between the growth and no growth schemes each year; however, it does not seem to represent the fact that double the number of businesses would be using the Metro to transport freight. It would be predicted that if the number of vehicles removed from the road doubled, then the savings in both accidents and money would also roughly double. The graph above shows that this is not the case; in fact, this is not even close to the
Table 4 Data without projected growth

\begin{tabular}{llllll}
\hline Businesses involved & $\begin{array}{l}\text { Money saved } \\
\text { by scheme }\end{array}$ & $\begin{array}{l}\text { Accidents saved } \\
\text { by scheme }\end{array}$ & & \multicolumn{2}{l}{ Casualties } \\
\cline { 5 - 6 } & & & Fatal & Serious & Slight \\
\hline $25 \%$ make 1 trip & $£ 33,945.20$ & 667.2 & 7.4 & 70.8 & 926.6 \\
$50 \%$ make 1 trip & $£ 65,700.10$ & 1237.8 & 15.2 & 139.7 & 1717.5 \\
$100 \%$ make 1 trip & $£ 135,965.40$ & 2506.2 & 33.0 & 293.4 & 3465.5 \\
$100 \%$ make 2 trips & $£ 240,916.00$ & 4358.2 & 59.7 & 528.1 & 6037.8 \\
\hline
\end{tabular}


Fig. 10 Comparison of growth inclusive/exclusive scheme
Fig. 11 Money saved versus number of businesses
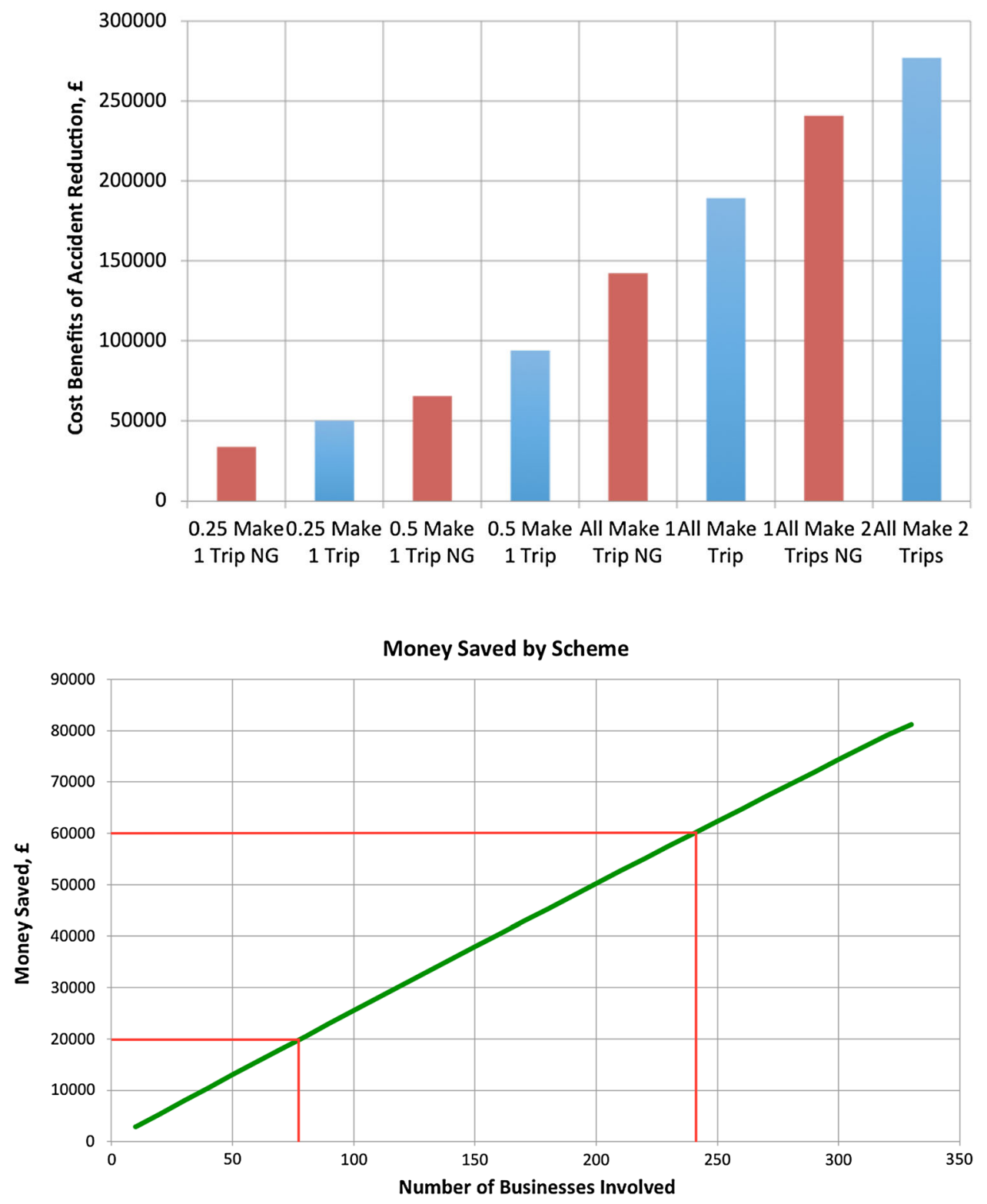

relationship. There is only ever a fractional difference between the schemes.

\subsection{Money Saved by Scheme}

The number of businesses was increased in increments of ten, from 10 to 330; the relevant data such as reduction of flows were altered and the input file for each number of businesses was run through COBALT. The relationship was found to be highly linear, with only minor fluctuations. This graph would allow a local authority to determine the number of businesses that would need to be involved in the scheme to gain the same savings in accident costs as the initial investment. For example, as shown in Fig. 11, if the amount of investment in the scheme was $£ 20,000$, with around 80 businesses making one trip to the city centre weekly, the money invested would be reaped in accident savings. However, if the initial investment were larger, for example, at around $£ 60,000$, a much larger number of businesses would need to be involved to make it financially viable. This is as would be expected; however, a graph such as this would allow the local authority to decide if the initial money needed for the scheme to function would be a good investment, and to determine what the take-up of the scheme would have to be before the money was paid back.

These data do not include projected growth of the scheme. The data do also based on the assumption that half of the businesses involved would make one trip weekly to the city centre. The number of vehicles removed from the road in 2020 is predicted to be the same as the number 
Fig. 12 Businesses involved in scheme

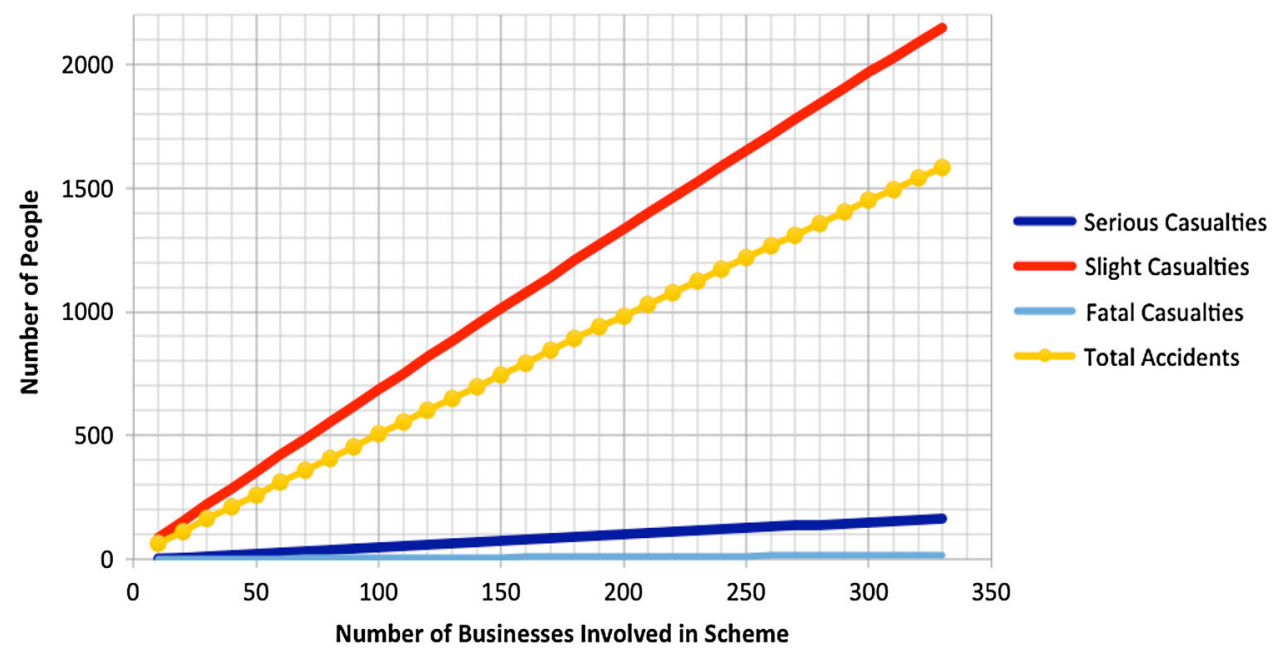

removed in 2035, so if the scheme grew and more businesses were involved, the data would need to be altered to accommodate this. The traffic flow data growth was predicted using the Defra traffic calculator, as before [15].

\subsection{Casualty Rates}

As data regarding the local severity split of the casualties were not available, the default accident rates from the parameter file were used. As expected, the number of casualties saved increases in a linear fashion with the number of businesses involved in the scheme; however, the gradient of each line varies (Fig. 12). The number of fatal casualties rises most slowly; it cannot be seen from the graph, however, with 10 businesses involved, there are no savings in fatal casualties, and with 330 businesses, there are 17.5 fatalities prevented. This is in contrast to the 'slight casualties' section, which rises from 86.2 to 2146.2 . This is clearly because slight casualties are most common in traffic collisions, indeed this can be seen from the fact that the number of slight casualties prevented is greater than the total number of accidents. This is presumably due to the fact that there is often more than one person in a vehicle, and that usually two vehicles are involved in a collision.

\section{Observations Presented By Study}

\subsection{Monetary Savings}

It is evident from the COBALT results that even a small reduction in the number of vehicles on the road can have a significant effect on the costs of dealing with collisions. It was predicted before any analysis was performed that the scheme would produce a reduction in the number of crashes on the road; however, it was not thought that such large monetary savings could be made. Data from Fig. 11 shows that with 40 businesses involved in the scheme, making one trip weekly into the city centre, the monetary savings are just over $£ 10,000$, showing that the take-up of the scheme does not necessarily need to be high to have a positive impact on traffic flows in the local area. However, the larger the scheme grows, the more of an effect the scheme will have. As expected, monetary savings increase with inclusion of businesses, so the more companies are encouraged to participate in such a scheme, the greater impact it will have.

\subsection{Accident Savings}

Regardless of any monetary savings that the scheme may bring, the reduction in casualties that could be achieved would have a large impact on local communities. If all 329 businesses studied reduced their travel by one journey weekly, 2,146 casualties could be prevented, 17 of which would be fatal. Even with just 10 businesses involved, 3 serious and 86 slight injuries could be prevented, demonstrating again that even a small reduction in flow would positively affect the roads surrounding Newcastle. The analysis using COBALT shows that such a scheme can not only positively impact the businesses directly involved in the scheme but could save lives and reduce the strain on hospitals and other emergency services through a reduction in the number of collisions.

Unfortunately COBALT does not have the ability to differentiate between different modes of transport, so there was no way of specifying that it would be HGVs and LGVs which were removed from the roads. This would further increase the safety of the public, particularly that of pedestrians and cyclists, as there is a much higher change of serious or fatal injury in a collision between a cyclist and a $\mathrm{HGV}$. Any number of reductions in casualties is a benefit to society, and thus, the scheme should be investigated further. 


\subsection{Modal Choice}

It is clear from all of the information presented throughout this report that a modal shift will be necessary for the transportation of freight in future years. Many separate sources have come to the conclusion that road-based freight transportation cannot continue to grow in the manner which is has done in recent years if we are to achieve emissions guidelines set out both by our government and the EU.

It is clear that there are many options available to logistics providers to transport freight, each with their own benefits. The most attractive option in terms of long-distance transportation is freight rail; however, this cannot be used to a large extent without being regenerated. Despite the investment needed, the positives offered by long-distance freight rail are numerous, allowing for large reductions in congestion, huge economies of scale and much lower fuel consumption when compared to road-based transportation. Many companies have achieved large emissions savings through a modal shift [56, 60], and where possible other businesses should follow. This is the underlying conclusion in almost all of the literature reviewed, and for such a shift to occur, there needs to be development and innovation in the way in which freight is transported. It is not enough to simply state that rail should be used; ways must be devised in which this is made easier and more convenient for the logistics providers, so that freight by rail becomes a desirable option once more.

For the carbon-neutral transport of freight in cities, it is clear that bicycle couriers and small electric vehicles are showing a surge in popularity for last mile operations. These also require investment, in terms of consolidation and distribution centres; however, the reductions in distance travelled by each package, noise emissions and carbon emissions are vast, and these vehicles should therefore be considered as a viable option for short distance freight transportation.

\subsection{Use of Metro Systems}

There is also significant evidence presented that short distance rail services such as metros have great potential for the transportation of freight, particularly in areas that have pre-existing infrastructure. This theory has been tested across Europe, with success in many cases, and could be mirrored in many cities across the UK. The majority of UK city centres are historic and therefore not suited for HGV or LGV transportation. A reduction in these types of vehicle could improve the image of the city whilst freeing many pedestrian walkways of parked vehicles unloading freight.

It is also clear that there are often gaps in the timetables of metro systems, which would allow a dedicated freight train to operate. Due to issues with safety and speed of unloading, combining passengers and freight on the same train would be unrealistic; however, with careful planning, it would often be possible to run a dedicated freight train and cause no disruption to passenger transport. This must be the case if such a system is to succeed, and great care must be taken to achieve minimal passenger disruption.

The use of inner city metro systems presents an opportunity to further utilize existing infrastructure, for relatively little investment, to cut emissions, and for faster and more efficient freight transportation.

\subsection{Newcastle upon Tyne}

It has been suggested that the Tyne and Wear Metro system is not currently running at its full potential. The operation of freight trains would allow for greater usage of the network, and due to the long headway between trains in this specific timetable, it is highly likely that there is a large enough gap in the timetable to allow for another train to run. Indeed if there was a large interest in the scheme, it may be possible for several extra trains to be included in the timetable.

The town of Killingworth shows great potential for the use of the Metro to transport freight. There are a large number of businesses situated in the town, the majority of which are a short distance away from the local metro station. The station is not underground, which allows for easier loading of goods, as they do not have to be transported from street level.

\section{Conclusion}

The evidence presented throughout this paper is demonstrative of the fact that a multimodal system using light rail is something which should be seriously considered for Newcastle upon Tyne. The Metro system has infrastructure that could be adapted for use in such a system, with many outdoor platforms and a significant amount of unused space at many stations. The timetable for the Tyne and Wear Metro is such that there is plenty of opportunity for the addition of at least one, if not several dedicated freight trains, with little or no disruption to passenger services. It has been shown through the use of software provided by the Department for Transport that there would be distinct savings in the number of casualties on the road, which in turn would present monetary savings through dealing with less collisions. The area surrounding Newcastle has a large number of businesses, and if these were to opt to transport their freight by metro, it could have a significant effect on inner city congestion, road collisions and emissions from transport. 
A modal shift of some description will be necessary to achieve targets set out by the Government, and a system with such high potential for emission reductions should be seriously considered.

\section{Future Work}

There are many industrial estates and business parks situated in the areas surrounding Newcastle, with the majority being in close proximity to a Metro station. Over time, it may be that a trial system is implemented in one of these towns, which would require significant collaboration between separate businesses, Nexus and the local authority. Before a trial system is developed, it would be necessary to contact each of the businesses and find detailed information about their usage of the scheme, for example, their current choice of transport, the volume of goods which they would transport, and the frequency at which they would use the system.

It would also be beneficial to find other methods of data capture, to ensure that the model presented is accurate. This was one of the major difficulties; often the relevant information is not easily available. In the long term, much of the data such as accident rates, speed limits and traffic flow could be obtained through discussion with the local authority, to ensure the relevance and accuracy of the modelling.

Only one small section of the viability of this scheme has thus far been analysed. It would be valuable to model the system using other software to find out more information. Particular areas that need further study include:

- The Tyne and Wear Metro timetable should be studied in depth, to determine the optimum placement of a freight train to minimize disruption to passenger services.

- A thorough look should be taken at the current Metro carriages, to see if these would be suitable for the transportation of freight, or if a new vehicle would need to be used.

- Research should also be undertaken into the use of driverless vehicles to transport freight. This would keep the running costs of the system low, as a driver would not have to be employed. This may not be viable; however, it would be beneficial to at least consider as an option.

- A study into the use, location and development of an Urban Consolidation/Distribution Centre should be completed. As demonstrated, these facilities allow for a much more efficient multimodal system, and the location of such a centre in Newcastle should be considered.

- Market research should be completed for a wide number of businesses, in order to ascertain the potential for take-up of the scheme. If it is found that the desire to participate in such a scheme is very low, then there is little point implementing it in its current form.

- A model should be developed to look at the carbon efficiency of using the Metro to transport freight. Little data could be found regarding emissions from the Tyne and Wear Metro, and such a study would be necessary to see if it could compete with other modes of transport in this area. A key reason behind the implementation of such a scheme would be to reduce $\mathrm{CO}_{2}$ emissions, and for that to occur the Metro would have to present significant savings over road-based freight transportation.

- The potential for such a system should be studied in many of the towns around Newcastle that are connected to the city centre via the Metro.

These forms of analysis would allow the scheme to be assessed from all angles, and once further examination has been completed, the feasibility of using the Tyne and Wear Metro to carry freight can be properly evaluated.

Open Access This article is distributed under the terms of the Creative Commons Attribution 4.0 International License (http://crea tivecommons.org/licenses/by/4.0/), which permits unrestricted use, distribution, and reproduction in any medium, provided you give appropriate credit to the original author(s) and the source, provide a link to the Creative Commons license, and indicate if changes were made.

\section{References}

1. Abbott D, Marinov MV (2015) An event based simulation model to evaluate the design of a rail interchange yard, which provides service to high speed and conventional railways. Simul Model Pract Theory 52:15-39

2. AEAT (2010) Light goods vehicle- $\mathrm{CO}_{2}$ emissions study: final report. [Online] Available at http://www.lowcvp.org.uk/news, dftpublishes-study-on-light-goods-vehicle-co2-emissions_1421.htm. Accessed 15 Apr 2015

3. Allen J, Browne M, Woodburn A, Leonardi J (2012) The role of urban consolidation centres in sustainable freight transport. Transp Rev 32(4):473-490

4. Arvidsson N, Browne M (2013) A review of the success and failure of tram systems to carry urban freight: the implications for a low emission intermodal solution using electric vehicles on trams. Eur Transp 54:1825-3997

5. Behrends S, Lindholm M, Woxenius J (2008) The impact of urban freight transport: a definition of sustainability from an actor's perspective. Transp Plan Technol 31(6):693-713

6. Bontekoning YM (2004) Is a new applied transportation research field emerging? A review of intermodal rail-truck freight transport literature. Transp Res Part A 38(1):1-34

7. Browne M (2011) Evaluating the use of an urban consolidation centre and electric vehicles in central London. IATSS Res 35(1):1-6

8. European Commission (2011) White paper on transport-roadmap to a single European transport area-towards a competitive and resource-efficient transport system. Publications Office of the European Union European Commission, Luxembourg

9. Craig AJ (2013) Estimating the $\mathrm{CO}_{2}$ intensity of intermodal freight transportation. Transp Res Part D 22:49-53 
10. CrashMap (2015) CrashMap. [Online] Available at www.crash map.co.uk Accessed 26 Apr 2015

11. CYLEX (2015) Map of Benton Square Industrial Estate. [Online] Available at http://www.newcastle-upon-tyne.cylex-uk.co.uk/ map/benton\%20square\%20industrial\%20estate.html. Accessed 3 Apr 2015

12. CYLEX (2015) Map of Harvey Combe from Newcastle Upon Tyne. [Online] Available at http://www.newcastle-upon-tyne. cylex-uk.co.uk/map/harvey\%20combe.html. Accessed 3 Apr 2015

13. Dablanc L (2013) Commercial goods transport, Paris, France. Paris, IFSTTAR

14. DECC (2013) Greenhouse gas emissions. [Online] Available at https://www.gov.uk/government/policies/reducing-the-uk-sgreenhouse-gas-emissions-by-80-by-2050. Accessed 15 Apr 2015

15. Defra (2010) How do I predict future traffic flows from available counts and what part does TEMPRO play? [Online] Available at http://www.laqm.defra.gov.uk/documents/TEMPRO_guidance. pdf. Accessed 13 Apr 2015

16. Delivery O (2015) Outspoken! Delivery. [Online] Available at http://www.outspokendelivery.co.uk/. Accessed 19 Apr 2015

17. DfT (2011) Domestic activity of GB-registered heavy goods vehicles. [Online] Available at https://www.gov.uk/government/ uploads/system/uploads/attachment_data/file/8966/domesticactivity-of-GB-registered-heavy-goods-vehicles.pdf. Accessed 15 Apr 2015

18. DfT (2011) Road freight economic, environmental and safety statistics. [Online] Available at www.gov.uk/government/uploads/ system/uploads/attachment_data/file/8968/road-freight-economicenvironmental-safety-statistics.pdf. Accessed 15 Apr 2015

19. DfT (2013) Traffic counts. [Online] Available at www.dft.gov. $\mathrm{uk} /$ traffic-counts/area.php?region=North+East\&Ia=Newcastle + upon+Tyne. Accessed 15 Apr 2015

20. DfT (2014) Low Emission HGV Task Force: Recommendations on the use of methane and biomethane in HGVs. [Online] Available at https://www.gov.uk/government/uploads/system/uploads/ attachment_data/file/287528/taskforce-recommendations.pdf. Accessed 15 Apr 2015

21. DfT (2015) English road safety comparison website closes on 27 March 2015. [Online] Available at https://www.gov.uk/govern ment/news/english-road-safety-comparison-website-closes-on27-march-2015. Accessed 9 Apr 2015

22. DfT (2015). Vehicle Licensing Statistics: Quarter 4 (Oct-Dec) 2014. [Online] Available at https://www.gov.uk/government/ uploads/system/uploads/attachment_data/file/421337/vls-2014. pdf. Accessed 15 Apr 2015

23. Endole (2015) Companies in NE12 8ET. [Online] Available at http://www.endole.co.uk/company-by-postcode/ne12-8et. Accessed 3 Apr 2015

24. Endole (2015) Companies in NE12 9SW. [Online] Available at http://www.endole.co.uk/company-by-postcode/ne12-9sw. Accessed 3 Apr 2015

25. Endole (2015) Companies in NE12 9SZ. [Online] Available at www.endole.co.uk/company-by-postcode/ne12-9sz. Accessed 3 Apr 2015

26. Endole (2015) NE12 5UJ. [Online] Available at: www.endole.co. uk/company-by-postcode/ne12-5uj. Accessed 3 Apr 2015

27. FGM-AMOR (2015) Moving Europe forward. [Online] Cyclelogistics Available at: http://cyclelogistics.eu/docs/111/D6_9_FPR_ Cyclelogistics_print_single_pages_final.pdf. Accessed $19 \mathrm{Apr}$ 2015

28. Franco J (2009) UK Pledges Electric Car and PHEV Subsidies. Octane Week

29. Google (2015) Google maps. [Online] Available at https://www. google.co.uk/maps/. Accessed 23 Apr 2015
30. Government (2015) Speed limits. [Online] Available at https:// www.gov.uk/speed-limits. Accessed 15 Apr 2015

31. Headicar P (2009) Transport policy and planning in Great Britain, 1 st edn. Taylor \& Francis, New York

32. HMRC (2013) Moving goods by road. [Online] Available at https://www.gov.uk/moving-goods-by-road. Accessed $15 \mathrm{Apr}$ 2015

33. IMechE (2009) Rail freight: getting on the right track. [Online] Available at http://www.imeche.org/docs/default-source/keythemes/Rail_Freight_Report.pdf?sfvrsn=0. Accessed 15 Apr 2015

34. LocalStore (2015)Shops. [Online] Available at www.localstore. co.uk/a/402/killingworth/. Accessed 3 Apr 2015

35. Marinov M (2012) Urban freight movement by rail. J Transp Lit 7(3):87-116

36. Motraghi A, Marinov MV (2012) Analysis of urban freight by rail using event based simulation. Simul Model Pract Theory 25:73-89

37. Nexus (2014) Metro strategy 2030. [Online] Available at http:// www.nexus.org.uk/sites/default/files/Metro\%20Strategy\% 20Background\%20document.pdf. Accessed 17 Apr 2015

38. Nexus (2015) Journey planner. [Online] Available at: http:// jplanner.travelinenortheast.info/nexus. Accessed 23 Apr 2015

39. Nexus (2015) Journey planner. [Online] Available at http:// jplanner.travelinenortheast.info/nexus. Accessed 23 Apr 2015

40. Nexus (2015) Metro map. [Online] Available at http://www. nexus.org.uk/sites/default/files/Zone\%20Map\%20TVM\%20 Map_2.pdf. Accessed 4 May 2015

41. OLEV (2015) Take-up of plug-in car grant continues to rise. [Online] Available at https://www.gov.uk/government/news/takeup-of-plug-in-car-grant-continues-to-rise. Accessed 15 Apr 2015

42. OLEV (2015) Ultra low emissions vehicles. [Online] Available at www.gov.uk/government/organisations/office-for-low-emissionvehicles. Accessed 15 Apr 2015

43. Perry C (2014) HGV speed limits on dual carriageways. [Online] Available at https://www.gov.uk/government/speeches/hgvspeed-limits-on-dual-carriageways. Accessed 15 Apr 2015

44. Peugeot (2013) Peugeot electric partner van. [Online] Available at www.peugeot.co.uk/news/new-peugeot-partner-electric-van/. Accessed 15 Apr 2015

45. PTEG (2015). Delivering the future-new approaches to urban freight

46. Quorum (2015) Occupiers. [Online] Available at www.quor umbusiness.co.uk/space/occupiers/. Accessed 3 Apr 2015

47. Rail FO (2011) Road congestion implications of bigger HGVs. [Online] Available at www.freightonrail.org.uk/NoMegaTrucks RoadCongestionImpactsOfBiggerHGVs.htm. Accessed 15 Apr 2015

48. Reis V (2014) Analysis of mode choice variables in short-distance intermodal freight transport using an agent-based model. Transp Res Part A 61:100-120

49. Rooijen TV (2012). Local impacts of a new urban consolidation centre: the case of Binnenstadservice.nl. In: Procedia social and behavioural sciences. Mallorca

50. Schliwa (2015) Sustainable city logistics: making cargo cycles viable for urban freight transport. Rese Transp Bus Manag

51. SE (2013) Go electric. [Online] Available at http://www.smith electric.com/go-electric/less-expensive-to-incorporate-and-main tain/. Accessed 15 Apr 2015

52. SE (2013). Models and Configurations. [Online] Available at http://www.smithelectric.com/smith-vehicles/models-and-config urations/. Accessed 15 Apr 2015

53. Singhania V (2014) Urban freight distribution: council warehouses and freight by rail. Transp Probl 9:29-43

54. Smith WJ (2010) Can EV (electric vehicles) address Ireland's $\mathrm{CO}_{2}$ emissions from transport? Energy 35(12):4514-4521

55. SMMT (2014) UK new car registration. [Online] Available at http://www.smmt.co.uk/2015/01/uk-new-car-registrations-decem ber-2014/. Accessed 21 Apr 2015 
56. Tesco (2014) Our carbon footprint. [Online] Available at www. tescoplc.com/assets/files/cms/Resources/Environment/Our_Car bon_Footprint.pdf. Accessed 15 Feb 2015

57. Tesco (2015) Reducing our impact on the environment. [Online] Available at http://www.tescoplc.com/index.asp?pageid=632\# tabnav. Accessed 22 Apr 2015

58. TfL (2014) Cycle superhighways. [Online] Available at http://www. tfl.gov.uk/campaign/cycle-superhighway-consultations. Accessed 19 Apr 2015

59. Transport DF (2013) COBALT user guids. [Online] Available at: https://www.gov.uk/government/uploads/system/uploads/attach ment_data/file/262973/cobalt-user-manuel.pdf. Accessed 26 Apr 2015

60. TWFP (2010) Tesco sets the pace on low carbon and efficiency. Queens Printer and Controller of HMSO
61. TWFP (2015) Freight maps. [Online] Available at http://www. tyneandwearfreight.info/maps/freight/tyneandwear/freight_map. aspx. Accessed 23 Apr 2015

62. UNECE (2009) Glossary for transport statistics. [Online] Available at http://www.unece.org/trans/main/wp6/transstatglossmain. html. Accessed 22 Apr 2015

63. Woodburn AG (2003) A logistical perspective on the potential for modal shift of freight from road to rail in Great Britain. Int $\mathbf{J}$ Transp Manag 1(4):237-245

64. Yell (2015) Companies in Stephenson Industrial Estate. [Online] Available at www.yell.com/s/companies-stephenson+industrial+ estate-newcastle+upon+tyne.html. Accessed 3 Apr 2015

65. Chen Z, Han BM (2014) Simulation study based on opentrack on carrying capacity in district of Beijing-Shanghai high-speed railway. Appl Mech Mater 505-506:567-570 